\title{
Prevotella corporis
}

National Cancer Institute

\section{Source}

National Cancer Institute. Prevotella corporis. NCI Thesaurus. Code C86665.

A species of obligately anaerobic, Gram-negative, rod shaped bacteria assigned to the phylum Bacteroidetes. This species is nonmotile, non-spore forming, produces a black pigment, beta- $\mathrm{N}$-acetyl-glucosaminidase positive, but xylose arabinose cellobiose, rhamnose, salicin, sucrose, lactose, indole, esculin hydrolysis, alpha-fucosidase, betaglucosidase and glycine aminopeptidase negative. P. corporis is typically isolated from nonoral sites though a few strains have been isolated from dental root canal infections. 